\title{
E-LEARNING AND TEACHING IN HO CHI MINH CITY UNIVERSITY OF TECHNOLOGY AND EDUCATION - INITIAL EVALUATION OF EFFECTIVENESS AND FEASIBILITY MODEL ON A LARGE SCALE
}

\author{
Nguyen Thi Nhu Thuy ${ }^{1 i}$, \\ Lu Thi Mai Oanh ${ }^{2}$ \\ ${ }^{1}$ Ho Chi Minh City University \\ of Technology and Education, \\ Vietnam \\ 2University of Education, \\ VietNam National University, \\ Ha Noi, Vietnam
}

\begin{abstract}
:
E-Learning and Teaching is a modern method of teaching and learning based on information technology. In particular, during the industrial revolution 4.0, information technology and digitization develop strongly and rapidly in all countries, which make the traditional teaching method lose the leading position in modern education. Because E-Learning and Teaching allows the maximum exploitation of its features and utility in online teaching and learning, reduces training costs, time and brings convenience for learners anytime and anywhere. Recognizing the importance of online teaching and learning trends in the industrial revolution 4.0, Ho Chi Minh City University of Technology and Education (HCMUTE) has applied and implemented the E-Learning and Teaching system on the basis of teaching management systems such as LMS/FHQLMS and Google Classroom. This article contributes to describing the current situation and difficulties in the implementation of E-Learning and Teaching, aiming to build an ELearning and Teaching application on a large scale in HCMUTE in particular and Vietnam in general.
\end{abstract}

Keywords: HCMUTE, e-learning and teaching, LMS/ FHQLMS, industrial revolution 4.0

\section{Introduction}

The advent of E-learning and Teaching has made online training, teaching and learning become more diverse and plentiful thanks to the internet connection, the application of

i Correspondence: email ntnthuy@hcmute.edu.vn, oanhltm@vnu.edu.vn 
information technology (IT). E-learning is defined by ASTD (American Society for Training \& Development) as a set of applications and processes such as web-based learning, computer learning, virtual classroom and digital work. Online training includes the design and the content division over the Internet, local area network/wide area network (LAN/WAN), audio, video, satellite broadcasting, interactive television and CDROM ROM (Kaplan-Leiserson, 2002, para. 85). According to Alavi and Leidner (2001), online training is known as a form of the technology-based learning with a learning environment which has learner-to-teacher interaction; digital resources are mediated through IT. Therefore, the use of IT Communication plays an important role in providing contents related to the E-learning and Teaching-based design for lecturers' success in teaching and students' success in E-learning. This is a method of teaching and learning that many developed countries in the world, such as in Europe, North America, Australia, and many more other countries over the world have been applied for many years. University professors have effectively implemented and applied the online teaching and learning feature through the lecture modeling, helping learners take the initiative in their own time, funds and resources to complete their course effectively.

In Vietnam, online teaching and learning method (E-Learning and Teaching) is quite new. The method of first open education used in Vietnam was marked by the establishment of Hanoi Open University and Ho Chi Minh City Open University in 1993. Open education at that time as a term to describe the model, the educational system was designed towards "the approach to learning by many methods, in which emphasizing the development of the open education course material sources (based on modern technology platform) in all learning environments with various different forms" (Nguyen Hong Son, 2017). However, the actual implementation and outcomes of online teaching and learning method in Vietnam are still facing many difficulties due to lack of synchronization and implementation on a national scale. Most of the results achieved in Vietnam now are mainly based on the experience of implementing of each unit/school and the level of use of the teaching management system applied by the units/schools.

Catching the new trend in the industrial revolution 4.0, HCMUTE has inaugurated a Digital Teaching Room (DTR) with a total value of more than 300,000 USD that is capable of connecting online globally (March 31, 2015); has invested 1 million USD to prepare for the online teaching, learning and testing programs. On that basis, the university has obtained remarkable achievements over the past 5 years, namely: "The work of digital teaching is promoted with the opening of 5,200 classes for three modes of study: Ordinary mode, High-quality and Part-time with 5 million visits to the LMS site. Successfully organized 2 seminars on digital teaching. Continue to maintain and develop DTR, LMS, and film, edit video clips for seminars, lectures." (UTE, Self-assessment report for registration of verifying the higher education quality, 2016).

In addition, many workshops have also been organized since 2014 to now such as: E/M Learning 2013, E-learning trends for 2014 focused on a number of topics: Current trends of Blended Learning; E-learning process and Assessment in E/M Learning; Using 
E-learning Tools to Increase Learning Motivation; Individual Learning Plan as Part of Ecourse.

The purpose of the article is to describe and analyze HCMUTE's results in implementation of E-learning and Teaching to clarify the importance as well as the advantages and disadvantages in creating an online teaching and learning environment with a teaching and learning management system based on the LMS, FHQLMS, and so on. The article be addressed to answer the following main questions:

1) Which teaching management system are the lecturers applying the most and most effectively?

2) How do lecturers apply the LMS/FHQLMS teaching management system?

3) Which form of software/tool for teaching and communicating with students by "video meeting" do lecturers apply?

4) Satisfaction of students during E-learning process.

Finally, the author wants to clarify the importance of learners' assessment to perfect and upgrade the teaching and learning management system on LMS/FHQLMS towards Improving the performance of online teaching and learning on a large scale.

\section{Overview}

History of technology development shows that, in the mid-90s of the last century up to now, it's only 25 years but there has been a strong development when there were only 200 million times of using technology from Desktop PC, there have been 10 billion users between 2010 and 2020, and it is expected that the year of 2030 will reach 50 billion times of use. In addition, Web technology has also made progress through the Web 1.0 Information Network, Web 2.0 Communication network, Web 3.0 Collaboration Network and Web 4.0 Integration Network:

- Web 1.0 existed in the period of 1996-2004, in the form of Hypertext Web, was mainly read-only, one-way interaction level, the scope was mainly personal page, texting.

- Web 2.0 communication networks existed from 2004-2016, people began to emphasize the social Web, participated and interacted two-way, online social networking sites.

- Web 3.0 collaboration network and Web 4.0 integration network (i.e., existing since 2016 up to now, with trillions of uses, people build Apps for interacting and publishing content, AI and 3D applications), are the learning Web.

Associating with Web technology is educational technology (ET). Thanks to the convenience in technology application, education 4.0 has provided teachers and learners with basic information about innovation, courses, data updates, specifically:

1) ET 1.0: lecturers provide knowledge source, support traditional notes, and students learn passively. 
2) ET 2.0: lecturers advise, instruct more open technologies, project-based learning, there are student collaboration and exchange between schools.

3) ET 3.0: lecturers play a leading role in creating knowledge and the open learning to tackle student's creativity and Internet connection at national and international scales. (4) ET 4.0 has just appeared: emphasized support by the learning method based on artificial intelligence (AL), Big data, googles digitals, automatic robots, 3D printing. Students are self-reliant, have academic advisors and AI develop educational plans together, constantly update under the adaptive mechanism. Web-based e-Learning organizations (Mai Van Tinh, 2020).

In education 4.0, modern teaching and learning method - E-Learning and Teaching is determined by two basic and important factors: open course material source and method based on online teaching and learning management platform. According to Chodorow S (1996), Gibbons A (2000), E-learning has a lot of strengths when it allows teachers to modify contents simply and quickly. The management of learner activities is monitored to determine class participation status. Besides, learners also somewhat reduce the administrative burden and show their control over the contents, the learning sequence, the learning speed, the time as well as allowing them to adjust their experience to meet individual learning goals.

Several assessments of practice and E-learning have been recently published such as the research by Fiore, \& Stone, 2002; Burgess \& Russell, 2003; Kosarzycki, Salas, DeRouin, \& Fiore, 2003. The researches emphasize the real situation of E-learning application as well as evaluate the effectiveness in optimizing pedagogical features and open materials source. In particular, the research by Volery \& Lord (2000) reveals that the needs of university students for E-learning-based courses are becoming more diverse. Therefore, understanding E-learning-related issues such as the learning initiatives, the lecture contents, digital materials, technology, pedagogy and individuality needs to be explored in order to complete the system development. Besides, the lack of a theoretical or conceptual framework in many previous studies related to E-learning has also led to inconsistent results and raised questions about the factors that determine the effectiveness of E-learning.

The development and supply of online course materials is "Open Course Ware OCW" from Massasuset Institute of Technology (MIT)published online in October 2002 with the desire to "promote the learning of mankind around the world by creating a available knowledge website". A decade later, in 2012, MIT and Harvard university announced the creation of edX, the networking tool as the platform for massive open online course (MOOC) to provide undergraduate programs with a wide range of free majors for learners all over the world. These courses are primarily for online students, and some cases may offer credits or certification based on exams. The edX-platform network tool is able to help students interact with each other and with lecturers via online forums. Currently (2015), there is about 1.5 million people using edX (Nguyen Hong Son, 2017). 
In Vietnam, the research on e-learning and teaching just breaks of at finding out about the real situation of the popularity of E-learning and teaching as well as assessing some related learning tools expressed through the subjects. Typical types of online training such as TBT-technology - based training, CBT-computer-based training, WVTweb-based training, online learning/training and distance learning. With its advantages, E-learning and teaching model is being accepted and applied widely in big cities in Vietnam. However, the current E-learning is still heavy on management and the use of the system's resources has not shown high efficiency while the majority is statistical. Up to now, there has not yet been a comprehensive research to assess students' E-learning situation as well as how the university has operated to manage and organize the effective implementation of E-learning application in the teaching program of teaching staff. Therefore, the article will assess the real situation of applying E-learning in universities to show the correlation with students' academic results, method of management, organization, and E-learning teaching activities in order to make timely adjustments to help the teaching process bring the most optimal results.

\section{Survey area}

HCMUTE was formed and developed on the basis of Technical Education College Department - established on October 5, 1962. On September 21, 1972, the school was renamed Nguyen Truong To Technical Education College Center Thu Duc and was upgraded to Thu Duc University of Education in 1974. On October 27, 1976, the Prime Minister signed a decision to establish Thu Duc University of Technical Education on the basis of Thu Duc University of Education. In 1984, Thu Duc University of Technical Education merged with Thu Duc Industrial High School and changed its name to Ho Chi Minh City University of Technology and Education. In 1991, Ho Chi Minh City University of Technology and Education merged with School of Technical Education 5 and has developed to this day.

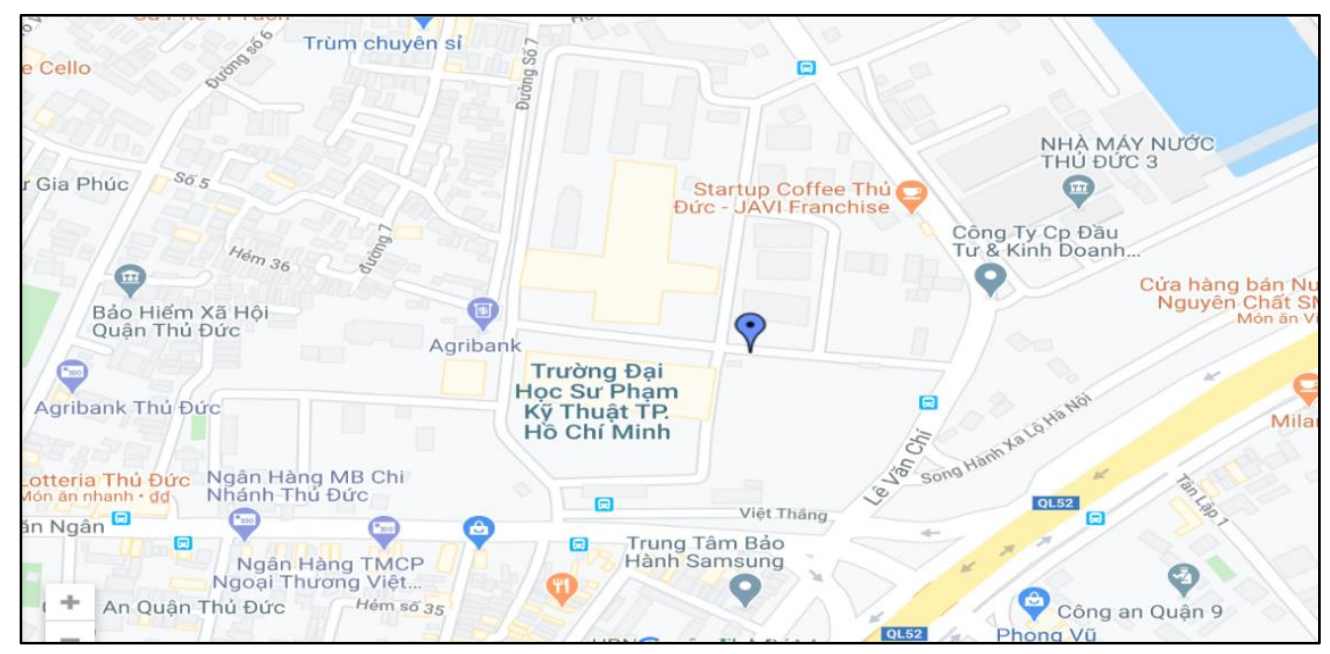

Figure 1: Google Map 
Located at No. 1 Vo Van Ngan, Linh Chieu Ward, Thu Duc District, belonging to the northern gateway of Ho Chi Minh City, about $10 \mathrm{~km}$ from the city center, with the campus I area (the main campus) is $174,247 \mathrm{~m}^{2}$, the campus II is $44,408 \mathrm{~m}^{2}$, HCMUTE has a very convenient transportation location, can use many means to move. With the advantages of location, space, and long history of development, the university has become a good quality learning facility with many utilities. This is a university with a long history of training in science and technology - applications, providing for the needs of high-quality technical labor of society. The university has a large number of students studying and doing research in various majors and is one of the top universities in the area of Ho Chi Minh City in training high-quality human resources to meet the needs of society.

HCMUTE's LMS system has been put into application and implemented since 2013(UTE, Self-assessment report for registration of verifying the higher education quality, 2016). Up to now, most of the university's lecturers have used the E-Learning and Teaching method on LMS with tens of thousands of student interactions.

\section{Research methods}

The data source of the article is based on the survey results from the Office of Quality Assurance, and statistics of Digital Teaching Center from 2015 to 2020, HCMC University of Technology and Education, specifically:

Quality Assurance Office's survey was conducted in April 2020. This article is based on the encryption of data from Quality Assurance Office's survey of the university, in which:

- Total votes sent: 55,949 votes.

- Results obtained: 55,905 votes.

After being cleaned, the remaining data was 55,403 votes that were eligible to make statistics; in which 745 subjects and 681 lecturers were surveyed. The data was cleaned, encrypted and processed by SPSS software.

The statistics from the digital learning center are encoded and processed via excel in the form of images and charts by the authors.

\section{Analysis results and discussion}

The university's educational philosophy is "Humanity, Creativity, and Integration". The common meaning of the university education philosophy is "The community of managers, lecturers, students and stakeholders of the HCMUTE participates in the process of educating, inspiring and supporting every student to become competent, conscientious and responsible individuals; to bear in students' minds the importance of new skills, skills of global citizens, entrepreneur skills and other core skills" (According to the educational philosophy, HCMUTE). The education philosophy and practical application have shown the 
importance of determining the core competencies of higher education in order to restructure the knowledge building, the building of framework of national qualifications; and get international recognition. Therefore, education in the context of technology 4.0 needs to be changed in the learning model. The quality of teaching depends on the method, content, learners, and educators. Therefore, online education needs to encourage, motivate teachers to use the teaching technology, foster the digital education skills and consider approaching appropriate technology.

\subsection{Teaching management system and e-learning and teaching implementation platform}

LMS stands for Learning Management System, this is an application software that allows the management and operation of documents, instructions, monitoring, reporting, and provision of electronic education technologies. It is also known as E-Learning online education for courses or training programs. Currently, LMS has three forms: Exclusive LMS (WebCT/Blackboard, D2L, and so on), Open source LMS (Moodle, Sakai), Cloudbased LMS (Google Driver, YouTube, Skype, and many others Web services). This management system allows educational institutions and enterprises to conduct online training courses.

Specifically, in the US in 2017, the most commonly used type of LMS was Blackboard Learn, with 1185 schools (32.24\%), followed by Canvas with 713 schools (19.04\%); 678 schools use Moodle (18.44\%), etc. (Mai Van Tinh, 2020, Seminar collection, University of Education), (see Table 5.1a).

Table 5.1a: Statistics of schools using LMS in the US in 2017 Number order

\begin{tabular}{|l|l|c|c|c|c|}
\hline \multirow{2}{*}{$\begin{array}{l}\text { Type of LMS } \\
\text { in use }\end{array}$} & \multicolumn{2}{|c|}{$\begin{array}{c}\text { Number of schools } \\
\text { and usage rates }\end{array}$} & \multicolumn{2}{c|}{$\begin{array}{c}\text { Totality enrollment } \\
\text { in Spring, 2017 }\end{array}$} \\
\cline { 3 - 6 } & $\mathbf{N}$ & $\mathbf{\%}$ & $\mathbf{N}$ & $\mathbf{\%}$ \\
\hline 1 & ANGEL & 34 & 0,92 & 124.679 & 0,63 \\
\hline 2 & Blackboard Learn & 1185 & 32,24 & 7.383 .086 & 37,40 \\
\hline 3 & Canvas & 713 & 19,40 & 4.773 .367 & 24,18 \\
\hline 4 & D2L & 360 & 9,79 & 2.314 .816 & 11,73 \\
\hline 5 & Moodle & 678 & 18,44 & 2.611 .762 & 13,23 \\
\hline 6 & Sakai & 107 & 2,91 & 757.643 & 3,84 \\
\hline 7 & Pearson & 105 & 2,86 & 353.686 & 1,79 \\
\hline 8 & Other & 494 & 13,44 & 1.420 .744 & 7,20 \\
\hline 9 & Total & 3.676 & 100,00 & 19.739 .783 & 100,00 \\
\hline
\end{tabular}

Source: Mai Van Tinh, 2020, Seminar collection, University of Education.

In Europe, the most commonly used type of available LMS in universities is the Moodle platform, with 1,043 schools (65\%), followed by Blackboard Learn with 192 schools (12\%), 64 schools use llias (4\%), unlike 304 schools that use other platforms such as Sakai, Claroline, Itslearning, GUNET eClass, Stud.IP, Olat, Canvas, D2L Brightspace, 
ClassFronter, Others (accounting for about 19\%) (Mai Van Tinh, 2020, Seminar collection, University of Education).

In HCMUTE, LMS has been put into operation since 2014 (according to the Decision No.564/QD-DHSPKT-TCCB, June 17, 2014 on the establishment of Digital Teaching Center based on the E/M Learning Technical Training Department of Faculty of High Quality Training) with the main platform - Pearson Education (supported free by Arizona State University (ASU) in 2013), this platform is used for the ordinary training program. In 2018, the university received support from Blackboard, which is used for the high-quality training program. Over six years of implementing the digital teaching training courses according to E-Learning and Teaching method for the ordinary training mode and more than two years for high quality training mode, the number of online interactions of students and lecturers is very large; especially the Blackboard platform, although it is only two years old, the number of interactions, assignments and discussions is relatively high (Table 5.1b).

Table 5.1b: Teaching platform (Unit: turn)

\begin{tabular}{lcc}
\hline & Person Education & Blackboard \\
\hline Number of student interactions & 356,596 & 222,012 \\
\hline Number of trainers interaction & 26,644 & 54,087 \\
\hline $\begin{array}{l}\text { Number of assignments (essay, multiple choice) } \\
\text { submitted by students }\end{array}$ & 4,188 & 2,85 \\
\hline Number of interaction, discussion of students & 23,274 & 16,984 \\
\hline
\end{tabular}

Source: Compiled from Digital Teaching Room, HCMUTE.

The above results show that the world has been changing greatly in educational technology; applying E-Learning and Teaching methods on the basis of LMS of universities in Europe and the United States has been quite diverse and plentiful. Although HCMUTE's the application of E-Learning and Teaching method on the platform of Person Education and Blackboard is quite new, compared to the world's roadmap, there has been initial successes in online teaching and learning.

\subsection{The encouraging policies and the level of applying the online teaching management system}

\subsubsection{The encouraging policies}

In order to apply the online teaching management system, the university and lecturers have analyzed the context as well as the situation of applying the teaching management system in the world so as to make initial assessments in implementing and applying it to the university's practices. On that basis, Faculties, Academic Affairs Office, and Digital Teaching Room develop and determine the specific training objectives (knowledge, attitudes, skills, competencies and qualities required in the Technology 4.0 context), identify goals, build subject output standards, build question banks, test sets, evaluate programs, plans to implement online teaching and learning, forms of testing, evaluation. 
In order to encourage teachers to apply the LMS platform in E-Learning and Teaching, the policies of supporting, encouraging the scientific research hours for lecturers who apply the digital teaching are clearly shown Decision No.293/QD-DHSPKT dated December 6, 2016 on the implementation of digital teaching activities; and Decision No. 875/QD-DHSPKT dated May 24, 2018 on amending and supplementing the Regulation of implementation of digital teaching activities. Whereby, the decision to support, encourage the first-time acceptance classes is as follows:

- Level 1: 50 hours of scientific research,

- Level 2: 70 hours of scientific research,

- Level 3: 100 hours of scientific research.

\subsubsection{The level of applying the online teaching management system}

In the spirit of the E/M Learning implementation plan for the period of 2013-2018 and the period of 2018-2013, under the direction and urging of the Center of digital teaching, Faculties and functional units of the university, the number of lecturers participating in digital teaching and the subjects applied in the university's LMS system has increased significantly from the first semester of the academic year 2014-2015 to the first semester of the academic year 2019-2020. Specifically:

Figure 5.2a: Number of classes that apply digital teaching (unit: number)

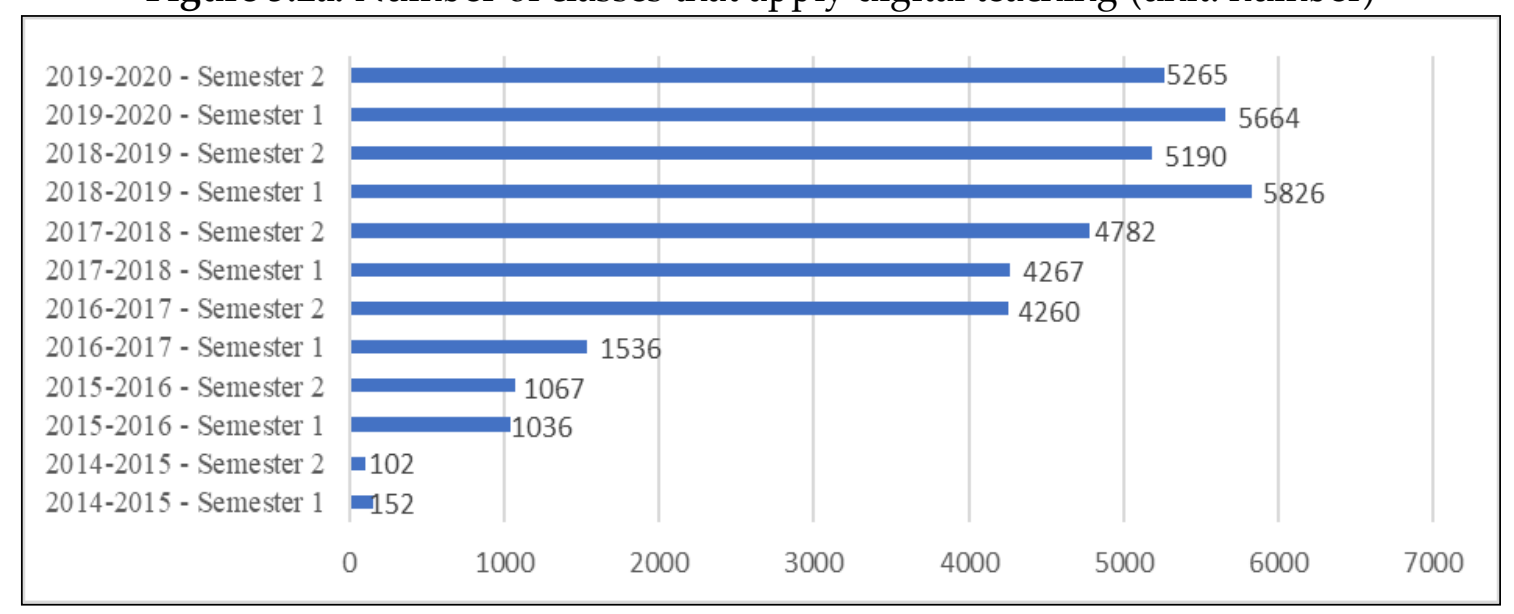

(Source: Compiled from Digital Teaching Room, HCMUTE)

The statistical results in Figure 5.2a reveal that in the first semester of the academic year 2014-2015, HCMUTE had initially implemented and had 152 classes applying digital teaching throughout the university. By the second semester of 2017-2018, the number of classes applied the digital teaching increased by 28 times compared to the first semester of the academic year 2014-2015. And by the second semester of the academic year 20192020, it increased nearly 35 times compared to the first semester of starting to apply digital teaching. This shows that the online teaching method is more and more widely used in HCMUTE. 
In parallel with the increase in the number of classes that apply digital teaching, the number of lecturers participating in digital teaching has also increased over the semesters of every academic year.

Figure 5.2b: Number of lecturers participating (unit: number)

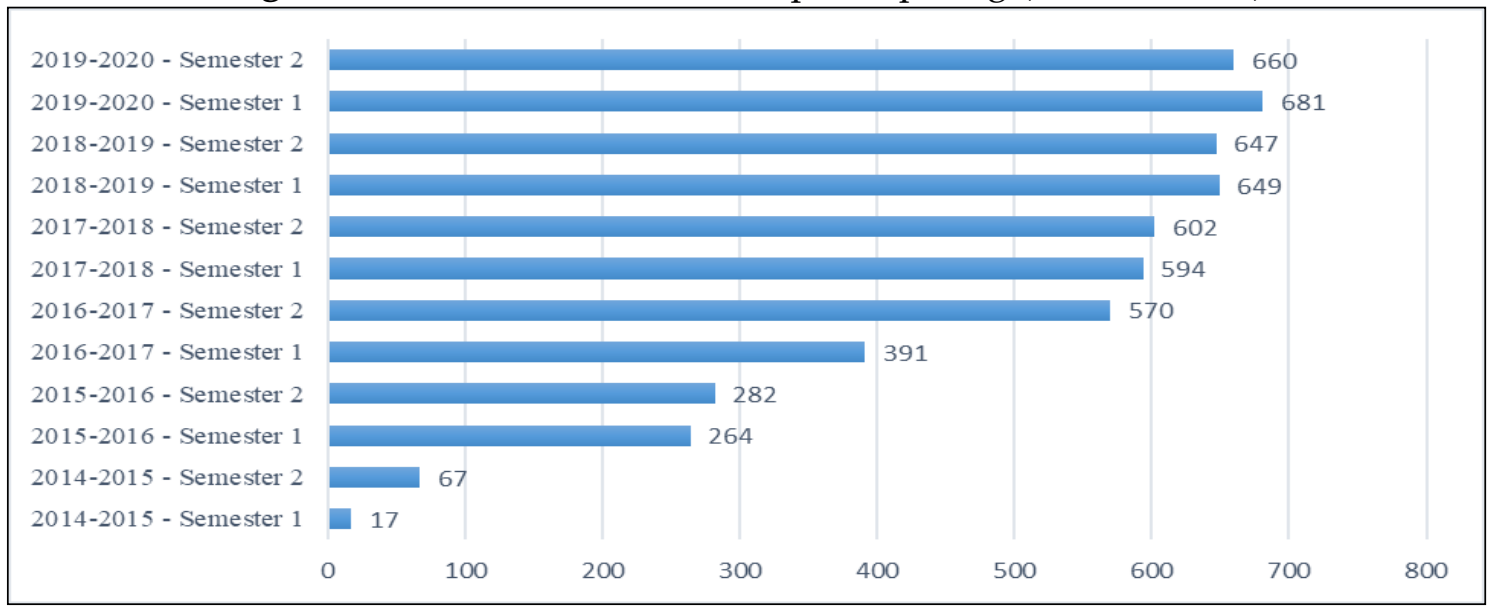

(Source: Compiled from Digital Teaching Room, HCMUTE)

The results in Figure 5.2b show that, there were only 17 lecturers applying digital teaching in the first semester of starting to implement and apply the digital teaching (Semester 1- 2014-2015), while the Semester 2 of the academic year 2016- 2017 saw the number of lecturers applying digital teaching reached 570 (nearly 34 times higher than the first semester of starting to apply digital teaching). Up to now, the number of lecturers applying digital teaching has been 660 (nearly 90\% of lecturers participate in digital teaching), an increase of nearly 39 times compared to the first semester - 2014-2015.

Most faculties' lecturers have applied the teaching management platform to implement teaching, in which the LMS/FHQLMS system is most commonly used (because this is the main system of the university, it has been implemented since 2013; and 2018 with two platforms, Person Education and Blackboard), followed by Google classroom and some other systems.

Table 5.1c: Teaching management system that teachers are applying

\begin{tabular}{|l|c|c|c|c|}
\hline & No & LMS/FHQ LMS & Google Classroom & other \\
\hline Faculty of Vehicle and Energy Engineering & 7,02 & 83,41 & 5,05 & 4,52 \\
\hline FME & 6,6 & 81,42 & 7,04 & 4,93 \\
\hline Faculty of Chemical \& Food Technology & 10,27 & 77,36 & 8,21 & 4,16 \\
\hline Faculty of Garment Technology and Fashion Design & 9,24 & 72,34 & 11,79 & 6,62 \\
\hline Faculty of Information Technology & 5,43 & 80,72 & 9,12 & 4,73 \\
\hline Faculty of Electrical and Electronics Engineering & 4,36 & 81,81 & 6,89 & 6,94 \\
\hline Faculty for High Quality Training & 19,43 & 68,16 & 7,01 & 5,41 \\
\hline Faculty of In Printing Engineering Technology & 7,53 & 75,56 & 7,13 & 9,78 \\
\hline Faculty of Applied Sciences & 3,63 & 80,78 & 9,33 & 6,25 \\
\hline Faculty of Economics & 6,81 & 76,8 & 11,63 & 4,76 \\
\hline Faculty of Political Ideology & 8,95 & 79,25 & 6,08 & 5,72 \\
\hline
\end{tabular}


Nguyen Thi Nhu Thuy, Lu Thi Mai Oanh

E-LEARNING AND TEACHING IN HO CHI MINH CITY UNIVERSITY OF TECHNOLOGY AND EDUCATION INITIAL EVALUATION OF EFFECTIVENESS AND FEASIBILITY MODEL ON A LARGE SCALE

\begin{tabular}{|l|c|c|c|c|}
\hline Faculty of Foreign Languages & 4,24 & 83,81 & 6,44 & 5,5 \\
\hline Faculty of Creative start-up & 10,21 & 72,77 & 7,66 & 9,36 \\
\hline Faculty of Construction Engineering Technology & 4,24 & 79,75 & 7,16 & 8,86 \\
\hline Institute of Technical Education & 3,41 & 89,69 & 4,75 & 2,15 \\
\hline Center for Physical Education and Defense & 75,48 & 21,38 & 0,83 & 2,31 \\
\hline Total & 11,68 & 75,31 & 7,26 & 5,75 \\
\hline
\end{tabular}

Source: Compiled from the survey results of the Quality Assurance Office, 4, 2020. HCMUTE.

The results in Table 5.1c show that, the whole school had 88,32\% of lecturers applying teaching management systems; in which the number of lecturers applying LMS/FHQLMS system accounted for the highest proportion $(75,31 \%)$, the number of lecturers applying Google Classroom and other systems accounted for relatively low percentage (respectively $7,26 \%$ and $5,75 \%$ ).

Table 5.1d: The level of applying LMS/FHQLMS system of lecturers

\begin{tabular}{|l|c|c|c|c|}
\hline & Level 1 & Level 2 & Level 3 & Level 4 \\
\hline Faculty of Vehicle and Energy Engineering & 12,9 & 18,74 & 24,62 & 43,74 \\
\hline FME & 16,5 & 19,52 & 26,85 & 37,13 \\
\hline Faculty of Chemical \& Food Technology & 17,79 & 17,95 & 24,52 & 39,74 \\
\hline Faculty of Garment Technology and Fashion Design & 5,85 & 16,76 & 24,14 & 53,25 \\
\hline Faculty of Information Technology & 10,47 & 14,83 & 28,75 & 45,96 \\
\hline Faculty of Electrical and Electronics Engineering & 10,96 & 15,61 & 25 & 48,43 \\
\hline Faculty for High Quality Training & 13,72 & 15,24 & 22,42 & 48,63 \\
\hline Faculty of In Printing Engineering Technology & 9,71 & 14 & 23,86 & 52,43 \\
\hline Faculty of Applied Sciences & 10,36 & 15,86 & 22,17 & 51,61 \\
\hline Faculty of Economics & 10,81 & 14,44 & 27,9 & 46,85 \\
\hline Faculty of Political Ideology & 14,02 & 15,06 & 24,44 & 46,48 \\
\hline Faculty of Foreign Languages & 10,14 & 9,8 & 27,04 & 53,01 \\
\hline Faculty of Creative start-up & 19,43 & 11,85 & 27,01 & 41,71 \\
\hline Faculty of Construction Engineering Technology & 7,72 & 12,89 & 24,55 & 54,85 \\
\hline Institute of Technical Education & 8,78 & 11,34 & 21,34 & 58,53 \\
\hline Center for Physical Education and Defense & 100 & 0,00 & 0,00 & 0,00 \\
\hline Total & 17,45 & 13,99 & 23,41 & 45,15 \\
\hline
\end{tabular}

Source: Compiled from the survey results of the Quality Assurance Office, 4, 2020. HCMUTE.

The results in Table 5.1d reveal that, among 16 surveyed Faculties, the Institute of Technical Education has the highest number of lecturers who apply the teaching management systems 96,59\% (including LMS/FHQLMS, Google Classroom, and other); while the Center for Physical Education and Defense, with the nature as a physical practice subject, had the least number of lecturers applying the teaching management system (only $24,52 \%$ ).

With the teaching management system applied by the lecturer, the level of class organization, provision of course materials, discussion and examination and assessment are also mentioned in the survey with different levels. Specifically: "Level 1: Lecturers only upload the course materials to LMS/FHQLMS; Level 2: Lecturers upload the course materials and the lecturing videos of chapters/lessons to LMS/FHQLMS; Level 3: Lecturers upload the course 
materials and the lecturing videos of chapters/lessons, require students to do the tests (quiz, assignment) on LMS / FHQLMS; Level 4: Lecturers upload the course materials and the lecturing video of chapters/lessons, require students to do the tests (quiz, assignment) and use the forum effectively to discuss with students on LMS/FHQLMS" (HCMUTE, Quality Assurance Office, 4/2020). The results in Table 5.1c present that the majority of lecturers in Faculties reached level 4, accounting for a higher proportion than levels 1, 2 and 3. In which, Lecturers of the Institute of Technical Education, Faculty of Construction, Faculty of Garment Technology and Fashion Design, Faculty of Foreign Language have the highest level of applying - Level 4.

In E-Learning and teaching, the learner is an indispensable factor. The number of students interacting in semesters also increased significantly.

Figure 5.2e: Number of students participating in the interaction (unit: number)

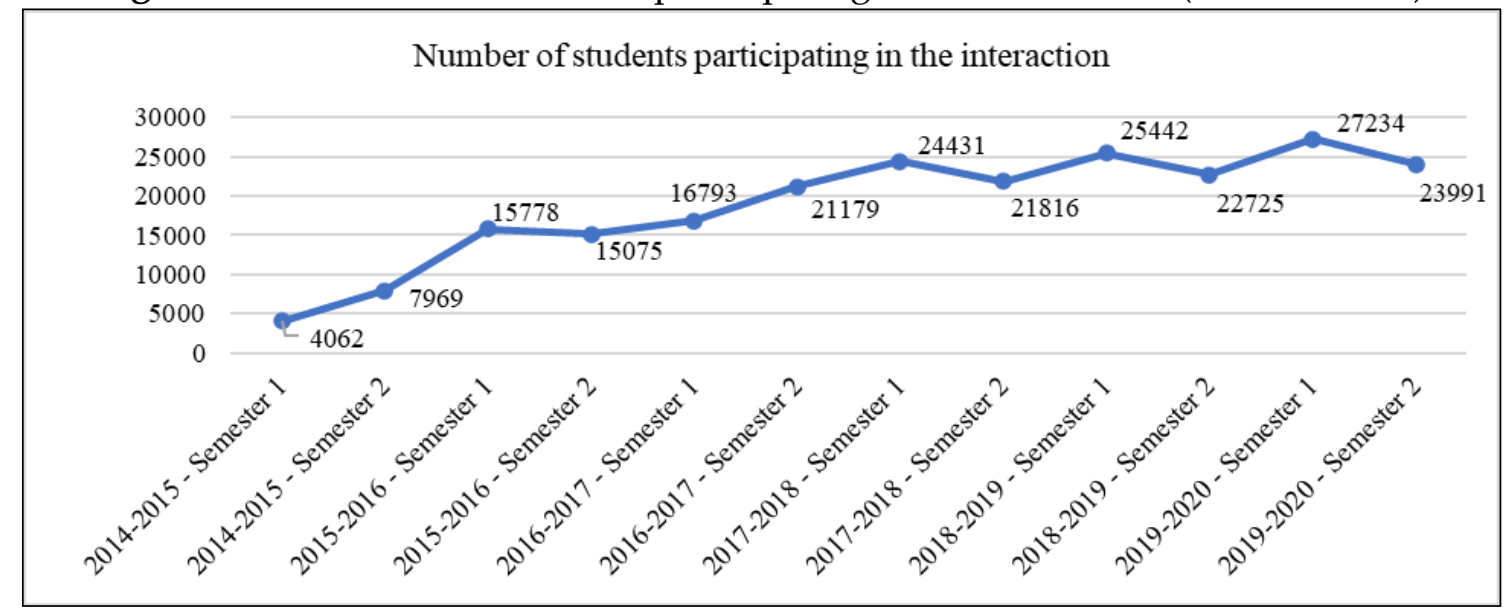

(Source: Compiled from Digital Teaching Room, HCMUTE)

The results in Figure 5.2e show that the number of students participating in interaction on the LMS platform rose greatly. Specifically, there were 4,042 students participating in the first semester of the academic year 2014-2015; the first semester of 2018-2019 increased to 24,431 students (6 times higher), by the first semester of the academic year 2019- 2020, there were 27,234 students interacting on LMS (an increase of 6.7 times compared to the first semester of starting to apply digital teaching). The above statistical results also demonstrate that, from the first semester of the academic year 20142015 to the first semester of the academic year 2017-2018, the number of students participating in interaction on LMS increased significantly among semesters. However, there was a significant change in the number of students participating in the interaction from the first semester of the academic year 2017-2018 to the second semester of the academic year 2019-2020, in particular, the number of students grew and declined significantly among semesters. This increase and decrease in the number of interactive students can be explained by the number of classes and lecturers participating in teaching goes up and goes down among semesters. 
The above results show that, E-Learning and Teaching at HCMC University of Technology and Education has achieved positive results in building courses on the Person Education and Blackboard platforms through the LMS and FHQLMS teaching management systems. The numbers of classes, the percentage of lecturers and the number of students participating in courses have constantly increased from 2014 to 2020.

\subsection{Tools and equipment in online teaching - learning}

Applying E-Learning and Teaching method must mention the use of the teachinglearning tools and equipment. In the online teaching and learning process, the use of equipment in online learning can greatly affect the online teaching and learning of teachers and students. Incidents can be encountered such as errors related to computer technique, telephone technique, internet connection, etc. Especially, if students only use learning tool such as phone/Tablet or internet access point (internet shop), it will be difficult to use other simultaneous features to participate in the online learning discussion process.

The survey results of the Quality Assurance Office in April 2020 show that the tools - output devices used by students in online learning are mainly laptops, Smart phones, and personal computers (PCs), ... (Figure 5.3a).

Figure 5.3a: Kind of terminal you use to study online (unit: \%)

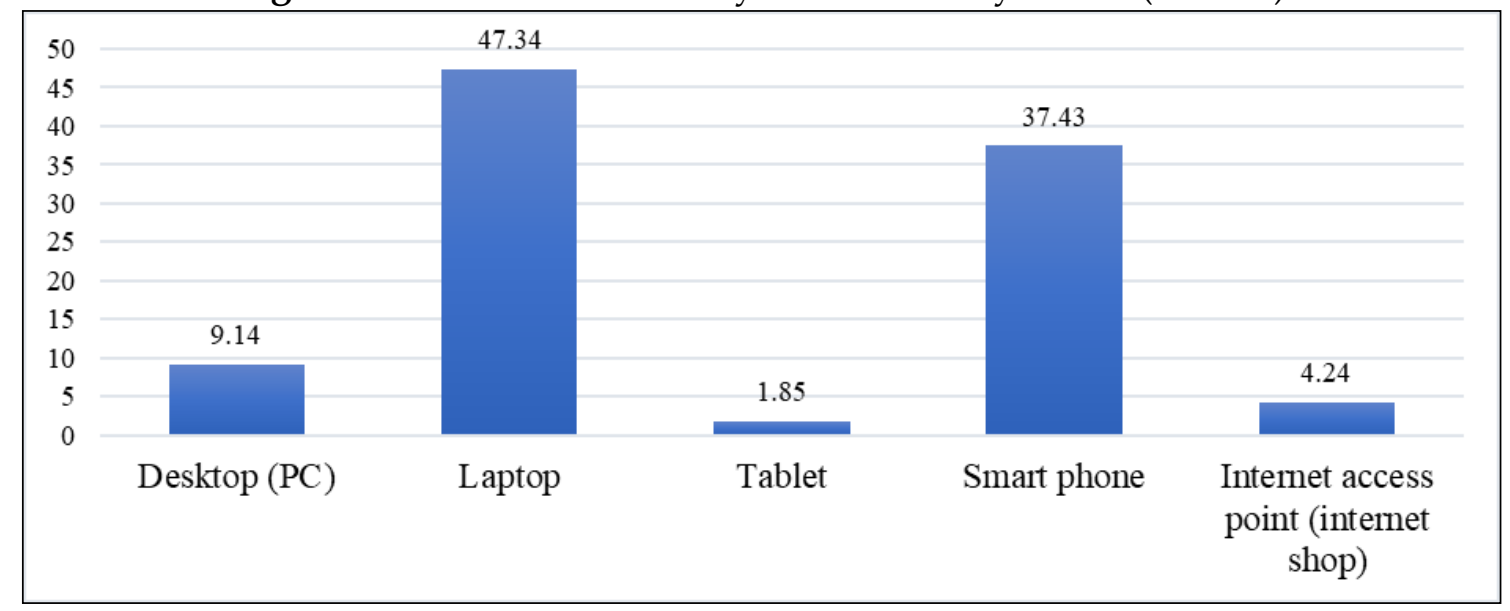

(Source: Compiled from the survey results of the Quality Assurance Office, 4, 2020. HCMUTE)

The results in Figure 5.3a reveal that the Laptop is the most used tool - device used by students for their online learning (accounting for 47,34\%), followed by the Smart phone (accounting for 37,43\%). The percentage of students using computers, tablets and going to internet shop to study is not high.

The method of direct communication between lecturers and students is performed through the supporting tools and devices from laptops, phones, tablets, etc... with software such as Moodle, Zoom meeting, Google classroom, Microsoft Teams, Google Meet, LMS/FHQLMS, Livestream on UTE - TV, Facebook. Through these platforms, 
lecturers provide full course materials (slides, video clips, ...); provide books, textbooks, reference materials, do quick tests (quiz, assignment) for each chapter, lessons to get marks.

According to the statistical results from a field survey conducted in April 2020 of Quality Assurance Office, lecturers make the most video meeting via Zoom software (accounting for 55,86\%); followed by Google Meet (accounting for 20,1\%). In addition, some lecturers use Facebook, Zalo, Jitsi Meet, Livestream on UTE -TV but the percentage is not high (Figure 5.3b).

Figure 5.3b: Video meeting (unit: \%)

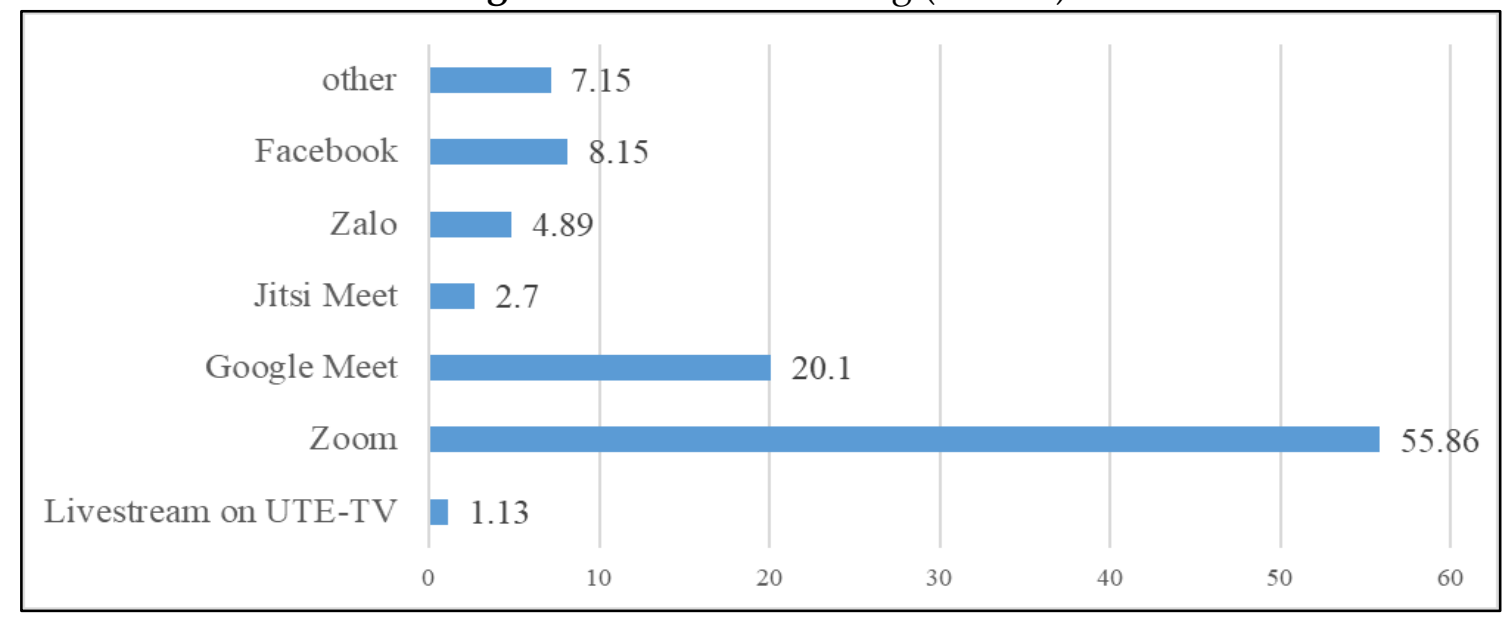

(Source: Compiled from the survey results of the Quality Assurance Office, 4, 2020.) HCMUTE

From this result, it is shown that the equipment and tools in online teaching and learning used by lecturers and students are quite diverse. In particular, most students are equipped with suitable devices for online learning such as Laptop, Smart phone. The software that supports Video meeting mostly used is Zoom, Google Meet.

Also, according to the survey results, many students assessed the internet connection weak, unstable, slow internet speed, unstable Wi-Fi. This makes the process of teaching and learning online interrupted easily, affecting the depressive psychology of students. Therefore, with equipment, tools and software that support online teaching and learning today, ensuring internet connection is an issue for the university, all teachers and students. This will help teachers and students have access to anywhere to support learning processes such as sharing and exploiting resources, building and managing classrooms in an online environment, doing online interaction, doing paper work and submitting papers online.

\subsection{Satisfaction of students about online teaching methods}

With the high proportion of students interacting during the semester, it is also important to consider the student's satisfaction level to make timely adjustments to online teaching and learning. Criteria for assessing student's satisfaction with teachers are also quite 
diverse. In which, there are some specific issues such as: lecturers provide materials, share resources on LMS, FHQLMS system; lecturers create a friendly, collaborative learning environment, encourage creativity in teaching and learning; during the course, students are given timely feedback on the assessment results to improve learning; lecturers are enthusiastic, timely answer questions and ready to absorb students' opinions; lecturers meet students' expectations; ...

The result of Figure 5.4a shows that most students are pleased with their lecturer. In general, the percentage of students who are pleased and very pleased with their lecturer makes up $63,79 \%$, the dissatisfaction only accounts for $4,60 \%$ and $31,60 \%$ of students feel normal. The assessment of student's satisfaction with their lecturer among Faculties has no significant difference.

Figure 5.4a: The level of student's satisfaction with the lecturer (unit: \%)

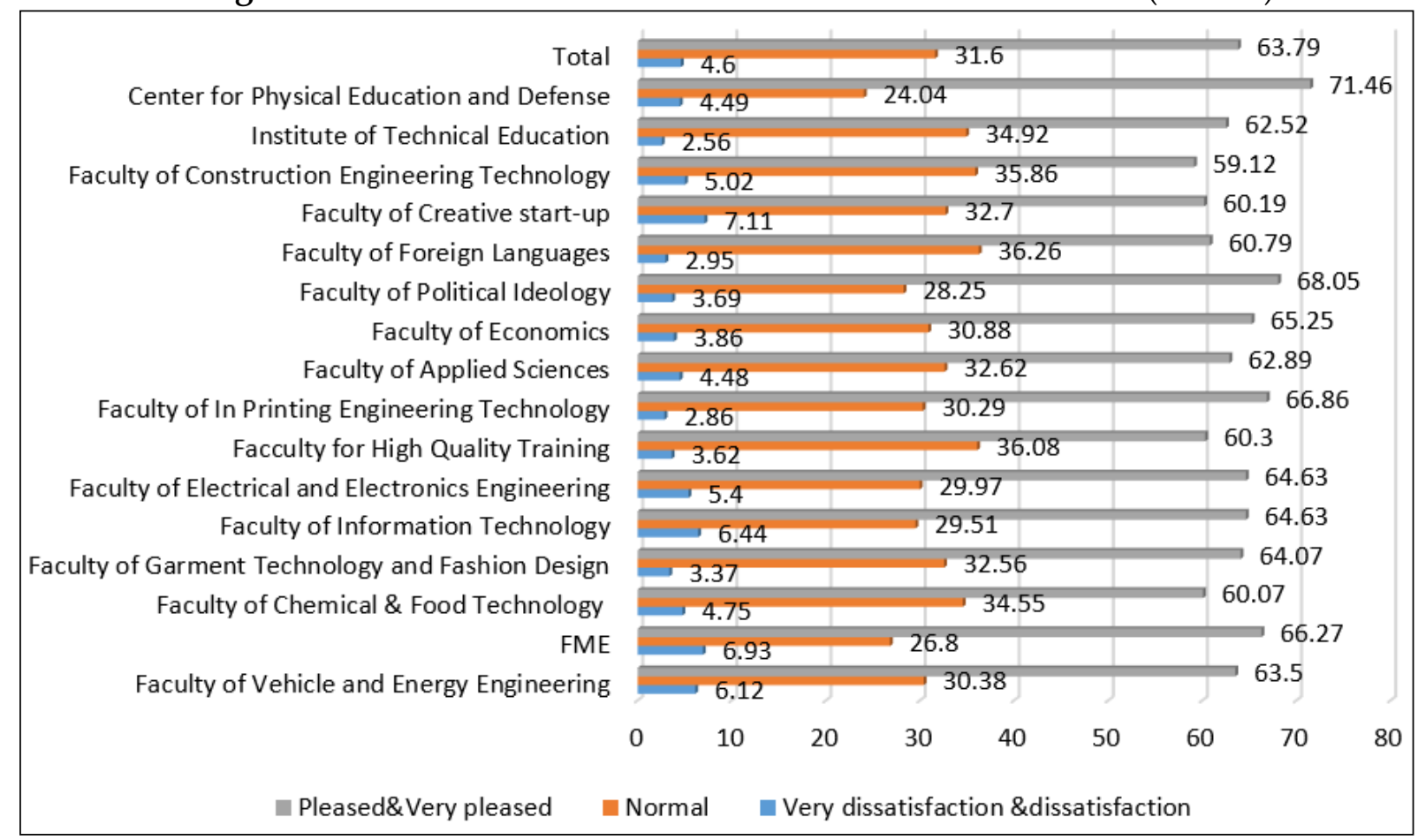

(Source: Compiled from the survey results of the Quality Assurance Office, 4, 2020. HCMUTE)

According to the results of the survey, the assessment level of student's satisfaction for their lecturers is quite high.

The results from Figure $5.4 \mathrm{~b}$ show the percentage of students of the Institute of Technical Education assessing the current online teaching organization being very pleased and pleased is the highest $(64,12 \%)$, followed by the assessment of students of High-quality Training Faculty (63,98\%), Creative Start-up Faculty (63,51\%); Garment Technology and Fashion Design Faculty (63,3\%). There is not much difference in the students' level of "being pleased and very pleased" in the remaining faculties. 
INITIAL EVALUATION OF EFFECTIVENESS AND FEASIBILITY MODEL ON A LARGE SCALE

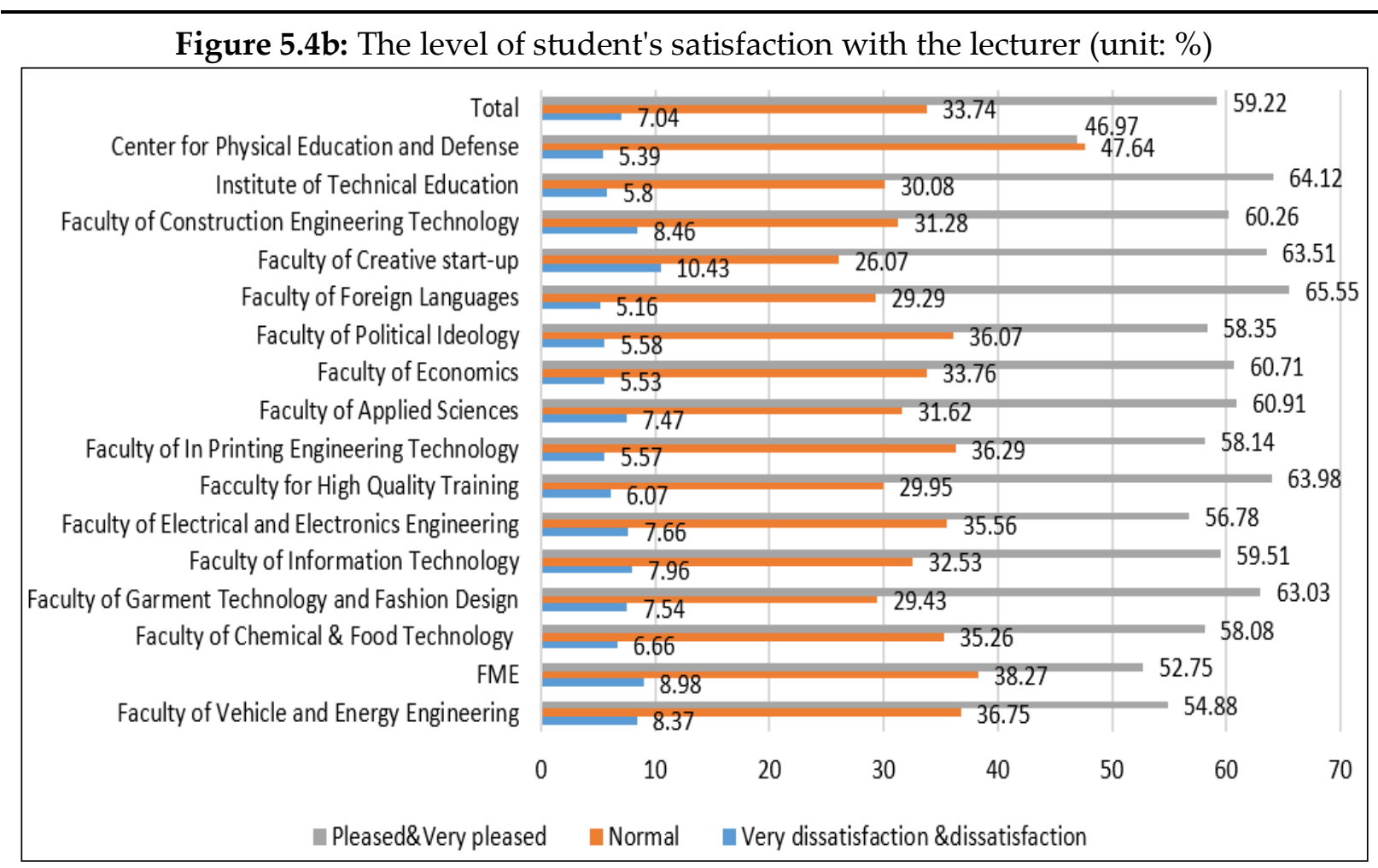

(Source: Compiled from the survey results of the Quality Assurance Office, 4, 2020. HCMUTE)

Thus, in E-learning and teaching, the problem that learners are interested in is still the final result that they receive from the lecturers, as well as the Faculties which implement online teaching. Therefore, the assessment of student's satisfaction in the online learning process will partly reflect the quality of the university's training when widely applying the online learning today. The student survey results at the Ho Chi Minh City University of Technology and Education reveal that, despite the difficulties in using online teaching and learning tools and equipment, along with the unstable internet connection, basically students assess it being pleased and very pleased with the current organization and implementation of the university.

\subsection{Disadvantages and advantages in online teaching and learning}

Properly assessing the disadvantages and advantages in the online teaching and learning organization will help the university, faculties, lecturers and students find their strengths and weaknesses to make timely adjustments in improving the quality of online teaching and learning today. Survey results with open-ended questions show that, during the process of implementation and application of online teaching, the university and lecturers, students have the following advantages and disadvantages:

\section{A. Advantages}

As the results analyzed above, along with the recognition from 25,552 students in the current online teaching of the university, there are certain advantages such as: 
Firstly, the arrangement and online teaching currently follow the actual schedule of students, which helps students to be convenient and proactive in approaching to the subject.

Secondly, the lecturers are basically very enthusiastic and friendly, ready to answer any questions, satisfy the students' desires within the limits of their ability.

Thirdly, on the LMS and FHQLMS systems, the lecturer provided full detailed \& intelligible documents, lectures. Do quick tests, discussions, and make assessments of the process objectively.

Fourthly, most lecturers have specific lecturing videos on LMS and FHQLM system so that students can learn and listen again.

Fifthly, most students in this survey have the means and tools to participate in online classes, the most popular of which are Laptop and Smart phones.

\section{B. Disadvantages}

Results of collecting opinions from 24,205 students show some disadvantages as follows:

Firstly, one of the factors affecting online learning performance today is the internet. In the implementation of online learning, an indispensable factor is the internet connection. The student's opinions reveal that, the internet transmission line and connection is unstable, resulting in the difficult access to the course, the phenomenon of jitter, lag in the video meeting has made it difficult for students to hear the lecture clearly.

Secondly, although the university's teaching management system is implemented mainly on LMS and FHQLMS with two main platforms: Person Education and Blackboard, most video meetings are done through free Zoom software, which makes lecturers and students out of the group due to time limit.

Thirdly, in online teaching - learning, the factors of self-study and self-research of students play an important and decisive role in the quality of online teaching. However, the results from 24,205 students show that students' ability to self-study has not yet met online learning.

Fourthly, some students still face many other difficulties (such as family economic conditions, the situation of Covid 19 disease) leading to fatigue and stress.

\section{Conclusion}

In terms of organizing teaching, E-Learning and teaching provides multimedia technologies to attract students, help students access to learning anytime, anywhere, and they can be proactive for learning, discovering knowledge. The above analysis results show that, at the Ho Chi Minh City University of Technology and Education, E-Learning and teaching implemented through LMS and FHQLMS systems on two main platforms, Person Education and Blackboard have achieved initial success. The number of lecturers taking part in digital teaching, the number of subjects applied online teaching as well as the number of interactive students rises every year. 
In terms of learning, the quality of online teaching is assessed by students as being pleased and very pleased, accounting for a relatively high percentage. This allows the university to maintain and replicate the $\mathrm{E}$ - Learning and teaching model, improving the quality of online training. HCMUTE is aiming to build a successful virtual university (UTEx) in the future.

Besides, learners also encounter a number of technical-related issues such as failing to meet the learning equipment, unstable internet connection, and software (zoom, Google Meet, Facebook, Zalo, Jitsi Meet, Livestream on UTE - TV) for learning not ensure continuity; some students have difficulties in life, leading to psychological stress, fatigue.

\title{
Conflict of Interest
}

The authors declare no conflicts of interest.

\section{Authors' Contribution}

Both authors contributed equally to the conception and writing of the manuscript.

\author{
About the Authors \\ Nguyen Thi Nhu Thuy is a Lecturer at Ho Chi Minh City University of Technology and \\ Education, Vietnam.
}

Lu Thi Mai Oanh works as Lecturer at University of education, VietNam National University, Ha Noi.

\section{References}

Alavi, M. \& Leidner, D. E. (2001). Research commentary: technology-mediated learning-a call for greater depth and breadth of research. Information Systems Research, 12,1-10.

Chodorow S. Educators must take the electronic revolution seriously. Acad Med. 1996; 71:22126.

Gibbons A, Fairweather P. Computer-based instruction. In: Tobias S, Fletcher J (eds). Training \& Retraining: A Handbook for Business, Industry, Government, and the Military. New York: Macmillan Reference USA, 2000:410-42.

Ho Chi Minh City University of Technology and Education (2016). Self-assessment report for registration of verifying the higher education quality, 198 pages.

Ho Chi Minh City University of Technology and Education, Center of digital teaching. Report on the acceptance summary of the digital teaching applying classes in 2014,2015, 2016, 2017, 2018, 2019, 2020.

Ho Chi Minh City University of Technology and Education. Quality Assurance Office. Report of student survey results on online teaching - learning activities of theoretical subjects in the second semester, the academic year 2019-2020. Ho Chi Minh City. No: 07 /bc-đbcl, April 17, 2020. 

INITIAL EVALUATION OF EFFECTIVENESS AND FEASIBILITY MODEL ON A LARGE SCALE

\begin{tabular}{lllll}
\hline Kaplan-Leiserson, & E. & (2002). & Elearning
\end{tabular}
http://www.learningcircuits.org/glossary.html. Accessed July 1, 2002.

Mai Van Tinh (2020). Technology \& Education Trend In 4.0 Era Seminar in Education In 4.0 Era University of Education, Vietnam National University, Ha Noi p.6-8, 41-42.

Nguyen Hong Son (2017). "Open education system". Continuing Education Department Ministry of Education and Training. (https://moet.gov.vn/giaoducquocdan/giaoduc-thuong-xuyen/Pages/default.aspx?ItemID=4545), updated on March 21, 2017.

Volery, T. \& Lord, D. (2000). Critical success factors in online education. The International Journal of Educational Management, 14(5), 216-223. 
Nguyen Thi Nhu Thuy, Lu Thi Mai Oanh

E-LEARNING AND TEACHING IN HO CHI MINH CITY UNIVERSITY OF TECHNOLOGY AND EDUCATION INITIAL EVALUATION OF EFFECTIVENESS AND FEASIBILITY MODEL ON A LARGE SCALE

Creative Commons licensing terms

Authors will retain the copyright of their published articles agreeing that a Creative Commons Attribution 4.0 International License (CC BY 4.0) terms will be applied to their work. Under the terms of this license, no permission is required from the author(s) or publisher for members of the community to copy, distribute, transmit or adapt the article content, providing a proper, prominent and unambiguous attribution to the authors in a manner that makes clear that the materials are being reused under permission of a Creative Commons License. Views, opinions and conclusions expressed in this research article are views, opinions and conclusions of the author(s). Open Access Publishing Group and European Journal of Open Education andE-learning Studies shall not be responsible or answerable for any loss, damage or liability caused in relation to/arising out of conflict of interests, copyright violations and inappropriate or inaccurate use of any kind content related or integrated on the research work. All the published works are meeting the Open Access Publishing requirements and can be freely accessed, shared, modified, distributed and used in educational, commercial and non-commercial purposes under a Creative Commons Attribution 4.0 International License (CC BY 4.0). 